\title{
A Computational Study of the Heterogeneous Synthesis of Hydrazine on $\mathrm{Co}_{3} \mathrm{Mo}_{3} \mathrm{~N}$
}

\author{
Constantinos D. Zeinalipour-Yazdi ${ }^{1}$ (I) C Richard A. Catlow ${ }^{1,2}$
}

Received: 20 March 2017 / Accepted: 8 May 2017 / Published online: 24 May 2017

(C) The Author(s) 2017. This article is an open access publication

\begin{abstract}
Periodic and molecular density functional theory calculations have been applied to elucidate the associative mechanism for hydrazine and ammonia synthesis in the gas phase and hydrazine formation on $\mathrm{Co}_{3} \mathrm{Mo}_{3} \mathrm{~N}$. We find that there are two activation barriers for the associative gas phase mechanism with barriers of 730 and $658 \mathrm{~kJ} / \mathrm{mol}$, corresponding to a hydrogenation step from $\mathrm{N}_{2}$ to $\mathrm{NNH}_{2}$ and $\mathrm{H}_{2} \mathrm{NNH}_{2}$ to $\mathrm{H}_{3} \mathrm{NNH}_{3}$, respectively. The second step of the mechanism is barrierless and an important intermediate,
\end{abstract}

$\mathrm{NNH}_{2}$, can also readily form on $\mathrm{Co}_{3} \mathrm{Mo}_{3} \mathrm{~N}$ surfaces via the Eley-Rideal chemisorption of $\mathrm{H}_{2}$ on a pre-adsorbed $\mathrm{N}_{2}$ at nitrogen vacancies. Based on this intermediate a new heterogeneous mechanism for hydrazine synthesis is studied. The highest relative barrier for this heterogeneous catalysed process is $213 \mathrm{~kJ} / \mathrm{mol}$ for $\mathrm{Co}_{3} \mathrm{Mo}_{3} \mathrm{~N}$ containing nitrogen vacancies, clearly pointing towards a low-energy process for the synthesis of hydrazine via a heterogeneous catalysis route.

Electronic supplementary material The online version of this article (doi:10.1007/s10562-017-2080-y) contains supplementary material, which is available to authorized users.

Constantinos D. Zeinalipour-Yazdi

c.r.a.catlow@ucl.ac.uk

$\triangle$ C. Richard A. Catlow

c.zeinalipour-yazdi@ucl.ac.uk

1 Kathleen Lonsdale Materials Chemistry, Department of Chemistry, University College London, London WC1H 0AJ, UK

2 School of Chemistry, Cardiff University, Cardiff CF10 1AD, UK 


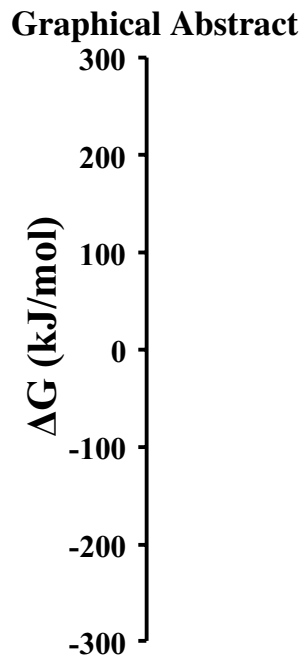

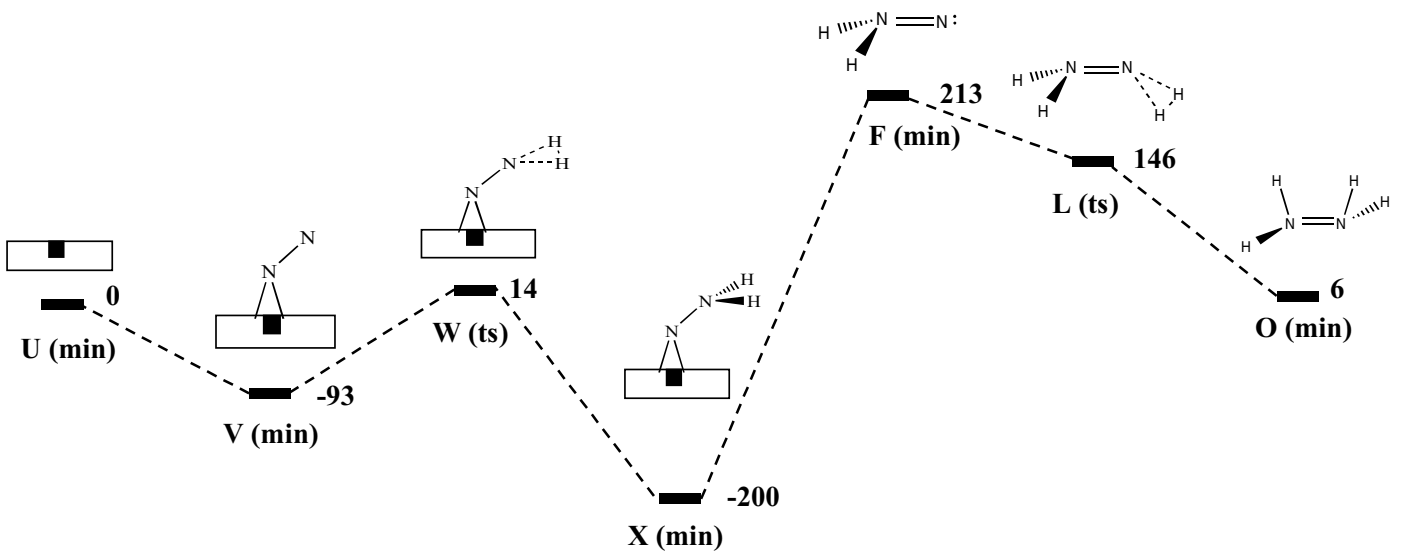

\section{Reaction coordinate}

\section{Introduction}

The development of alternative routes to convert $\mathrm{N}_{2}$ to ammonia $\left(\mathrm{NH}_{3}\right)$ and hydrazine $\left(\mathrm{H}_{2} \mathrm{NNH}_{2}\right)$ could have significant economic and environmental impact, since more that $50 \%$ of ammonia for soil fertilisers is produced industrially and the global annual production of hydrazine is more than 80 thousand tons [1]. Ammonia is industrially produced mostly via the classical Haber-Bosch $(\mathrm{H}-\mathrm{B})$ process [2-4], by a $\mathrm{Fe}-\mathrm{K}_{2} \mathrm{O}-\mathrm{Al}_{2} \mathrm{O}_{3}$ catalyst under high temperatures $\left(>400^{\circ} \mathrm{C}\right)$ and pressures $(150-200 \mathrm{~atm})$. Some production has shifted towards the Kellogg advanced ammonia process, which uses a graphite-supported alkali/ alkaline-earth promoted $\mathrm{Ru}$ catalyst and operates at milder conditions [5].

Hydrazine is produced by the Bayern ketazine process, which is a variation of the Olin Raschig process [6]. The two main reactions of this process are the formation and hydrolysis of 1,2-di(propan-2-ylidene)hydrazine (i.e. acetone azine),

$$
\begin{aligned}
& 2 \mathrm{Me}_{2} \mathrm{CO}+2 \mathrm{NH}_{3}+\mathrm{NaOCl} \rightarrow \mathrm{Me}_{2} \mathrm{C} \\
& \quad=\mathrm{NN}=\mathrm{CMe}_{2}+3 \mathrm{H}_{2} \mathrm{O}+\mathrm{NaCl}, \\
& \mathrm{Me}_{2} \mathrm{C}=\mathrm{NN}=\mathrm{CMe}_{2}+2 \mathrm{H}_{2} \mathrm{O} \rightarrow \mathrm{N}_{2} \mathrm{H}_{4}+2 \mathrm{Me}_{2} \mathrm{CO} .
\end{aligned}
$$

In brief, in this process ammonia is oxidised by sodium hypochlorite in acetone to form acetone azine (ketazine) which in the presence of water decomposes to hydrazine and acetone. A by product of the reaction is sodium chloride. The details of this process are: sodium hypochlorite $(\mathrm{NaOCl})$ solution, ammonia $\left(\mathrm{NH}_{3}\right)$ and acetone $\left(\mathrm{Me}_{2} \mathrm{CO}\right)$ are mixed at $35^{\circ} \mathrm{C}$. A solution results consisting of about $7 \%$ by weight acetone azine together with sodium chloride and excess ammonia. Ammonia is distilled off and returned to the reaction. The acetone azine-water-azeotrope (b.p. $95^{\circ} \mathrm{C}$ ) is distilled off leaving the sodium chloride solution. The acetone azine is hydrolyzed with water at temperatures up to $180^{\circ} \mathrm{C}$ and pressures of $8-12$ bar into an acetone and an aqueous hydrazine solution. The hydrazine solution is then concentrated by distillation.

$\mathrm{Co}_{3} \mathrm{Mo}_{3} \mathrm{~N}$ is one of the most active catalysts for ammonia synthesis at mild conditions, especially when doped with caesium [7-11]. In two recent density functional theory (DFT) studies we have identified possible sites for the adsorption and activation of the reactants of the ammonia synthesis reaction on a model $\mathrm{Co}_{3} \mathrm{Mo}_{3} \mathrm{~N}$ surface, with heterogeneity due to surface nitrogen vacancies [12]. Such vacancies are present in large concentrations even at ambient temperatures (i.e. $\sim 10^{13} \mathrm{~cm}^{-2}$ ) and can efficiently activate $\mathrm{N}_{2}$ [13]. In particular, we found that $\mathrm{N}_{2}$ can be activated at a surface cavity where $\mathrm{N}_{2}$ is bound side-on a $\mathrm{Co}_{8}$ cluster at the $16 e$ Wyckoff site or it can be activated at surface $3 \mathrm{f}$-nitrogen vacancies where $\mathrm{N}_{2}$ is activated in an end-on configuration [12]. There are other DFT studies that have shown that $\mathrm{N}$-vacancies can participate in the mechanism for ammonia synthesis, such as in the electrochemical reduction of ammonia on $\mathrm{Zr}, \mathrm{Nb}$, $\mathrm{Cr}, \mathrm{V}$ mononitrides [14-16] and in the two-phase solarenergy driven ammonia synthesis on metal-nitrides [17, 18]. End-on activated $\mathrm{N}_{2}$ also exists in $\mathrm{Fe}(0)$ complexes (i.e. $\mathrm{Fe}\left(\mathrm{Et}_{2} \mathrm{PCH}_{2} \mathrm{CH}_{2} \mathrm{PEt}_{2}\right)_{2}\left(\mathrm{~N}_{2}\right)$ ) found to be selective for the formation of hydrazine from $\mathrm{N}_{2}$ with $\mathrm{NH}_{3}$ forming at a ratio of 25:1 [19]. These complexes were initially designed to resemble the binding of $\mathrm{N}_{2}$ to FeMo-cofactor [20], the enzyme responsible for the biological fixation of nitrogen in nitrogenases, for which further atomistic details on the mechanism have recently been reported [21]. 
To assist our understanding of the hydrazine synthesis reaction, we have first modelled the reaction mechanism for associative synthesis of hydrazine and ammonia in the gas phase, via hybrid DFT calculations and also modelled how some of the intermediates can be formed on the surface of $\mathrm{Co}_{3} \mathrm{Mo}_{3} \mathrm{~N}$. The results of this paper are presented in the following order. First we present the various hydrogenated intermediates of the hydrazine and ammonia synthesis reaction in the gas phase. Then we present a gas-phase, free energy diagram that explores the kinetic pathway for hydrazine and ammonia synthesis. Lastly we present a new mechanism that shows how hydrazine could be synthesized over a heterogeneous catalyst (i.e. $\mathrm{Co}_{3} \mathrm{Mo}_{3} \mathrm{~N}$ ).

\section{Methods and Models}

Molecular open and closed-shell DFT computations have been perfomed with Gaussian 09 [22] with the use of Becke's three-parameter hybrid exchange functional [23] (XC) combined with the Lee-Yang-Parr non-local correlation functional [24], abbreviated as B3LYP. For the basis functions we have used the spherical version (i.e. $5 \mathrm{~d}, 7 \mathrm{f}$ ), the correlation consistent augmented valence triple zeta basis set [25-29], abbreviated as aug-cc-pVTZ.

The potential free energy diagrams were obtained by plotting the formation Gibbs free energy change $\left(\Delta G_{f, P E S}\right)$ of the various intermediates and transitions states with respect to gas phase reactants, given by the following expression,

$$
\Delta G_{f, P E S}=G_{N x H y}-\frac{x}{2} \cdot G_{N 2}-\frac{y}{2} \cdot G_{H 2}
$$

In the computed free energy changes we have included the entropy changes for gas phase molecules the vibrational energy of the adsorbates bound to a single metal atom, therefore entropy changes for the solid phase have been omitted. These were calculated at $\mathrm{P}=1$ atm and $\mathrm{T}=298.15 \mathrm{~K}$. The equation from which the vibrational energies of the adsorbates was calculated is given in the supporting information file. Intermediates and transition states (TS) have been confirmed using vibrational analysis, by the absence and presence of one imaginary vibrational frequency, respectively. Transition state structures were either located using the Synchronous Transit-Guided Quasi-Newton (STQN) method of Schlegel and co-workers $[30,31]$ or by scanning a particular bond length at a $0.05 \AA$ resolution and relaxing the remaining atoms. The imaginary frequency of the located TS was animated to ensure that it corresponds to the desired reaction coordinate. Every structure was calculated at a spin multiplicity (s.m.) of 1 , 3 and 5, but only the lowest energy structure is reported. Calculations were checked for spin contamination, which was found to be negligible. In most cases, the structure with s.m. $=1$ had the lowest energy. The molecular structure, point group (p.g.) symmetry, vibrational streching frequency $\left(\nu_{\mathrm{N}-\mathrm{N}}\right)$, bond length $\left(\mathrm{r}_{\mathrm{N}-\mathrm{N}}\right)$, spin multiplicity and formation energy $\left(\Delta \mathrm{G}_{\mathrm{f}}\right)$ of the various $\mathrm{N}_{\mathrm{x}} \mathrm{H}_{\mathrm{y}}$ intermediates are shown in Table 1. The table is partioned to show the various stable hydrogenation intermediates $\mathrm{N}_{\mathrm{x}} \mathrm{H}_{\mathrm{y}}$ that were found. These can assist infrared spectroscopic efforts in identifying the intermediates in the gas phase reaction mechanism. The intermediate of interest, $\mathbf{F}$, could be identified through IR spectroscopy as its $\nu_{\mathrm{N}-\mathrm{N}}$ differs by more than $400 \mathrm{~cm}^{-1}$ from that of isomeric $\mathbf{G}, \mathbf{H}$ and $\mathbf{I}$. Furthermore, Table 1 lists the computed free energies of formation of the various intermediates at $\mathrm{P}=1 \mathrm{~atm}$ and $\mathrm{T}=298.15 \mathrm{~K}$. These formation energies show the relative trends of the stability of the various intermediates of the same molecular weight and are therefore useful in the experimental isolation of such intermediates during the synthesis of ammonia and hydrazine. We find good agreement between the computed formation free energy of ammonia $-23 \mathrm{~kJ} / \mathrm{mol}$ with the one listed in thermeodynamic tables (i.e. CRC Handbook of Chemistry and Physics) $-27 \mathrm{~kJ} / \mathrm{mol}$, indicative that a relatively accurate computational methodology has been followed.

Periodic calculations were performed with the VASP code with a $650 \mathrm{eV}$ cutoff for the planewave expansion and the revPBE XC functional. A $4 \times 4 \times 1 \Gamma$-point centered MP grid for the $2 \times 2$ surface supercell with one $3 \mathrm{f}$-hollow nitrogen vacancy and a vacuum gap of $20 \AA$ was used. All calculations were spin-polarised.

\section{Results and Discussion}

\subsection{Hydrazine and Ammonia Synthesis in Gas Phase}

We have studied the associative mechanism for ammonia and hydrazine synthesis, where $\mathrm{N}_{2}$ does not dissociate but rather reacts directly with $\mathrm{H}_{2}$, which necessitates very high pressure rather than thermal activation of the reactants. This mechanism of ammonia synthesis in the gas phase can be directly compared to the associative mechanism occurring on the (111) surface of $\mathrm{Co}_{3} \mathrm{Mo}_{3} \mathrm{~N}$. The resulting free energy diagram for the associative mechanism of ammonia synthesis in the gas phase is shown in Fig. 1, where we only present the kinetic pathway (the pathway which has the lowest barrier for its rate-determining step (RDS)). We note that there is also another mechanism which proceeds via monotamic hydrogen atoms and provides an energetically viable alternative as a result of the high activation barrier of the first hydrogenation step $(730 \mathrm{~kJ} / \mathrm{mol})$ for the associative mechanism which based on the bond-dissociation enthalpy (BDE) of 
Table 1 Calculated at B3LYP/ aug-cc-pVTZ properties of the various $\mathrm{N}_{\mathrm{x}} \mathrm{H}_{\mathrm{y}}$ intermediates participating in the gas phase mechanism of ammonia synthesis

\begin{tabular}{|c|c|c|c|c|c|c|c|}
\hline & Formula & p.g. & State & $\mathrm{v}_{\mathrm{N}-\mathrm{N}}\left(\mathrm{cm}^{-1}\right)$ & $\mathrm{r}_{\mathrm{N}-\mathrm{N}}(\AA)$ & s.m. & $\Delta \mathrm{G}_{\mathrm{f}}(\mathrm{kJ} / \mathrm{mol})$ \\
\hline A & $: \mathrm{N} \equiv \mathrm{N}:$ & $\mathrm{D}_{\text {infh }}$ & Min & 2448 & 1.091 & 1 & - \\
\hline B & $\mathrm{H}-\mathrm{H}$ & $\mathrm{D}_{\text {infh }}$ & Min & [4417] & [0.7429] & 1 & - \\
\hline $\mathrm{C}$ & & $\mathrm{C}_{2 \mathrm{v}}$ & $\mathrm{TS}$ & 719 & 1.433 & 3 & 886 \\
\hline $\mathrm{D}$ & & $\mathrm{D}_{2 \mathrm{~h}}$ & $\mathrm{TS}$ & 954 & 1.467 & 1 & 768 \\
\hline $\mathrm{E}$ & $\stackrel{H}{\equiv}$ & $\mathrm{C}_{\mathrm{s}}$ & $\mathrm{TS}$ & 738 & 1.433 & 1 & 730 \\
\hline $\mathrm{F}$ & & $\mathrm{C}_{\mathrm{s}}$ & Min & 1208 & 1.336 & 3 & 352 \\
\hline G & & $\mathrm{C}_{2 \mathrm{v}}$ & Min & 1608 & 1.210 & 1 & 300 \\
\hline $\mathrm{H}$ & & $\mathrm{C}_{2 \mathrm{v}}$ & Min & 1647 & 1.234 & 1 & 236 \\
\hline I & & $\mathrm{C}_{2 \mathrm{~h}}$ & Min & 1652 & 1.235 & 1 & 215 \\
\hline $\mathrm{J}$ & & $\mathrm{C}_{2}$ & $\mathrm{TS}$ & 1136 & 1.429 & 1 & 746 \\
\hline $\mathrm{K}$ & & $\mathrm{C}_{2 \mathrm{v}}$ & $\mathrm{TS}$ & 1073 & 1.436 & 1 & 346 \\
\hline & & & & & & & \\
\hline $\mathrm{L}$ & & $\mathrm{C}_{\mathrm{s}}$ & $\mathrm{TS}$ & 1045 & 1.468 & 1 & 285 \\
\hline M & & $\mathrm{C}_{\mathrm{s}}$ & Min & 1434 & 1.314 & 3 & 474 \\
\hline $\mathrm{N}$ & & $\mathrm{C}_{2 \mathrm{v}}$ & $\mathrm{TS}$ & 909.2 & 1.477 & 3 & 179 \\
\hline $\mathrm{O}$ & & $\mathrm{C}_{2}$ & Min & 1107 & 1.433 & 1 & 145 \\
\hline $\mathrm{P}$ & & $\mathrm{C}_{2}$ & $\mathrm{TS}$ & 571 & 1.600 & 1 & 892 \\
\hline Q & & $\mathrm{C}_{1}$ & $\mathrm{TS}$ & 649 & 1.467 & 3 & 837 \\
\hline $\mathrm{R}$ & & $\mathrm{D}_{3 \mathrm{~d}}$ & Min & 1032 & 1.464 & 1 & 632 \\
\hline $\mathrm{S}$ & & $\mathrm{D}_{3}$ & Min & 392 & 2.218 & 3 & 399 \\
\hline $\mathrm{T}$ & & $\mathrm{C}_{3 \mathrm{v}}$ & Min & - & - & 1 & -23 \\
\hline
\end{tabular}

The parameters listed are the point group (p.g.) symmetry, the state, vibrational streching frequency $\left(\nu_{\mathrm{N}-\mathrm{N}}\right)$, bond length $\left(\mathrm{r}_{\mathrm{N}-\mathrm{N}}\right)$, spin multiplicity (s.m.) and formation energy $\left(\Delta \mathrm{G}_{\mathrm{f}}\right)$ of the various $\mathrm{N}_{\mathrm{x}} \mathrm{H}_{\mathrm{y}}$ intermediates. $\mathrm{P}=1 \mathrm{~atm}$ and $\mathrm{T}=298.15 \mathrm{~K}$. Values in brackets refer to the $\mathrm{H}-\mathrm{H}$ bond
$\mathrm{H}_{2}$ would cause the $\mathrm{H}-\mathrm{H}$ bond to break before the formation of intermediate $\mathrm{N}_{2} \mathrm{H}_{2}(\mathbf{F})$. However, we only consider the associative mechanism due to its relevance to the reaction occurring on the $\mathrm{Co}_{3} \mathrm{Mo}_{3} \mathrm{~N}$ surface. We find that for the gas phase reaction, the various mechanistic pathways generally consist of three activated steps, where 
Fig. 1 Gibbs free energy diagram for associative hydrazine and ammonia synthesis mechanism in gas phase calculated at B3LYP/aug-cc-pVTZ (5d,

$7 f)$. Free energies of formation of the various intermediates and transition states have been calculated using Eq. 1 and are tabulated in Table 1 at $\mathrm{P}=1 \mathrm{~atm}$ and $\mathrm{T}=298.15 \mathrm{~K}$

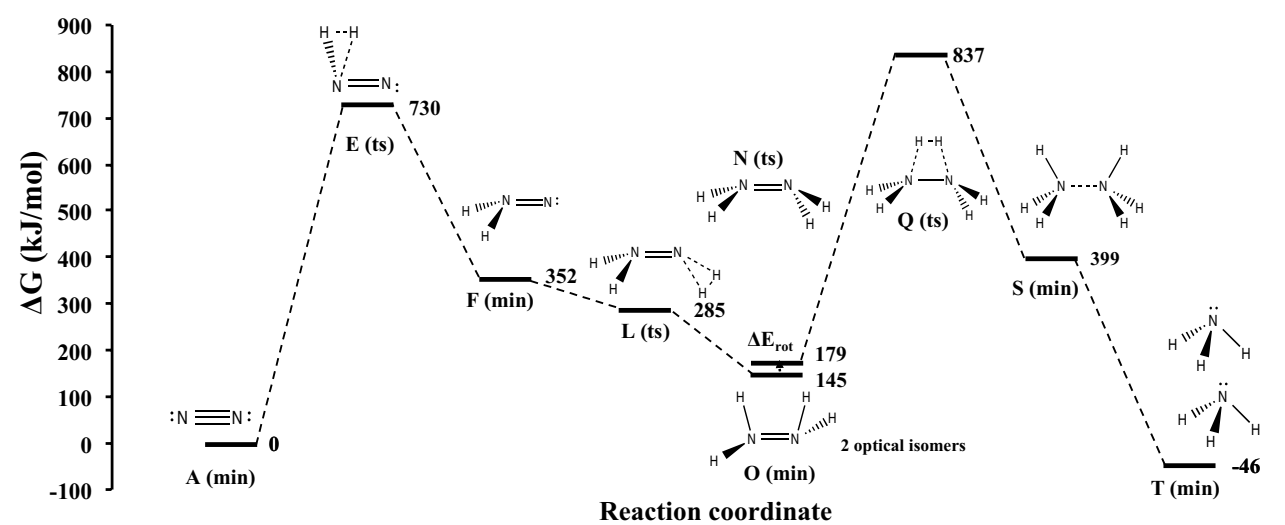

each step corresponds to a hydrogenation reaction of $\mathrm{H}_{2}$ with $\mathrm{N}_{2}$ forming $\mathrm{N}_{2}\left(\mathrm{H}_{2}\right)_{\mathrm{n}}(\mathrm{n}=0,1,2)$ intermediates. For the kinetic pathway only the first and the last hydrogenation steps have considerably high barriers, whereas in the second the barrier was essentially absent. The kinetic pathway was determined on the basis that its RDS had the lowest barrier among the four possible associative pathways studied. We find that the RDS step for ammonia synthesis in the gas phase (without a catalyst) has a barrier of $730 \mathrm{~kJ} / \mathrm{mol}$, which is followed by a barrier of $658 \mathrm{~kJ} / \mathrm{mol}$ which corresponds to the third hydrogenation step. From the relative barrier heights of the $1 \mathrm{st}$ and 3rd hydrogenation steps in Fig. 1 it is suggested that based on an associative mechanism, there would be some hydrazine formation during ammonia synthesis. This has been previously observed in glow discharge reactions of $\mathrm{N}_{2}$ and $\mathrm{H}_{2}$ over various solid surfaces (e.g. $\mathrm{SiO}_{2}, \mathrm{TiO}_{2}$, $\mathrm{MoO}_{3}, \mathrm{Al}_{2} \mathrm{O}_{3}, \mathrm{MgO}, \mathrm{Mg}(\mathrm{OH})_{2}$ ) having a zeroth order dependence on the reactants total pressure, producing 4-28\% hydrazine and 72-96\% ammonia [37]. The $658 \mathrm{~kJ} / \mathrm{mol}$ barrier could be overcome if the $\mathbf{O}$ isomer of hydrazine radiatively undergoes isomerization through intermediate $\mathbf{N}$ (see Table 1), which brings the hydrazine intermediate $\mathbf{N}$ to the right stereochemical structure to undergo subsequent hydrogenation to form $\mathrm{H}_{3} \mathrm{NNH}_{3}(\mathbf{S})$. We have calculated that this requires far-infrared radiation of a wavelength of $2842 \mathrm{~cm}^{-1}$. S thermally decomposes to form two ammonia molecules in a barrierless process. The intriguing aspect of this mechanism is that the 2nd hydrogenation step is barrierless, which corresponds to the adsorption of molecular hydrogen on the hydrogen pre-activated intermediate $\mathrm{N}_{2} \mathrm{H}_{2}(\mathbf{F})$. Interestingly we also found that this intermediate can form readily on (111)-surfaces of $\mathrm{Co}_{3} \mathrm{Mo}_{3} \mathrm{~N}$, at nitrogen vacancy sites. This intermediate in the gas phase reaction mechanism requires $730 \mathrm{~kJ} / \mathrm{mol}$ to form but only $107 \mathrm{~kJ} / \mathrm{mol}$ at the nitrogen vacancies on $\mathrm{Co}_{3} \mathrm{Mo}_{3} \mathrm{~N}$. We seek this intermediate and the mechanism for hydrazine synthesis in the associative mechanism for ammonia synthesis in the following section.

\subsection{Hydrazine Synthesis on $\mathrm{Co}_{3} \mathrm{Mo}_{3} \mathrm{~N}$}

In this study we have found that intermediate $\mathbf{F}$ on $\mathrm{Co}_{3} \mathrm{Mo}_{3} \mathrm{~N}$ can form at nitrogen vacancy sites, similar to its formation on $\mathrm{Mo}=\mathrm{NNH}_{2}$ [32] and $\mathrm{Fe}-\mathrm{NNH}_{2}$ [33] complexes and in a DFT study of the Schrock cycle molybdenum complex $\left[\mathrm{Mo}\left(\operatorname{hiptN}_{3} \mathrm{~N}\right)\right]$ [34]. It is noted that this activation site of $\mathrm{Co}_{3} \mathrm{Mo}_{3} \mathrm{~N}$ shows some similarities with the FeMo-cofactor with the main difference the bridging-N rather than bridging-S sites. A detailed study of the various adsorption sites on $\mathrm{Co}_{3} \mathrm{Mo}_{3} \mathrm{~N}$ surfaces is given in Ref. [13]. The D3-corrected adsorption energy of $\mathrm{N}_{2}$ is moderately exothermic, evidence that the adsorption of $\mathrm{N}_{2}$ at the nitrogen vacancies can occur at ambient temperatures. $\mathrm{N}_{2}$ in this position is activated by $11 \%$, based the adsorption induced $\mathrm{N}-\mathrm{N}$ bond lengthening. Once $\mathrm{N}_{2}$ is adsorbed to the surface in an end-on configuration it reacts with $\mathrm{H}_{2}$ coming from the gas phase by an activated step of only $107 \mathrm{~kJ} / \mathrm{mol}$ in order to form intermediate $\mathbf{X}$. The bonding of intermediate $\mathbf{X}$ resembles intermediate $\mathbf{L}$ in the gas phase mechanism. The optimal molar ratio of $\mathrm{N}_{2}: \mathrm{H}_{2}$ in the gas feed-stream is found to be $1: 1$, in order manifest $\mathrm{N}_{2}$ adsorption at nitrogen vacancies and $\mathrm{H}_{2}$ co-adsorption at $\mathrm{Co}_{8}$ clusters [13]. This prohibits poisoning of the nitrogen activation sites by chemisorbed hydrogen although we have previously shown via DFT that even at ambient $\mathrm{T}$, there are more than $10^{13}$ nitrogen vacancies per $\mathrm{cm}^{2}$ which can act as active sites for nitrogen activation [12]. The energy required to generate nitrogen vacancies, the vacancy formation energy (VFE) was found to be $162 \mathrm{~kJ} / \mathrm{mol}$ for three-fold (3f) bound nitrogen. This clearly suggests that if the reaction is run with a net input of energy of $213 \mathrm{~kJ} / \mathrm{mol}$ (see barrier for desorption of intermediate $\mathbf{X}$ from the nitrogen vacancy in Fig. 2) then nitrogen activation sites will constantly be present and replenished even if some hydrogen adsorption occurs at these sites, whose adsorption is generally more 


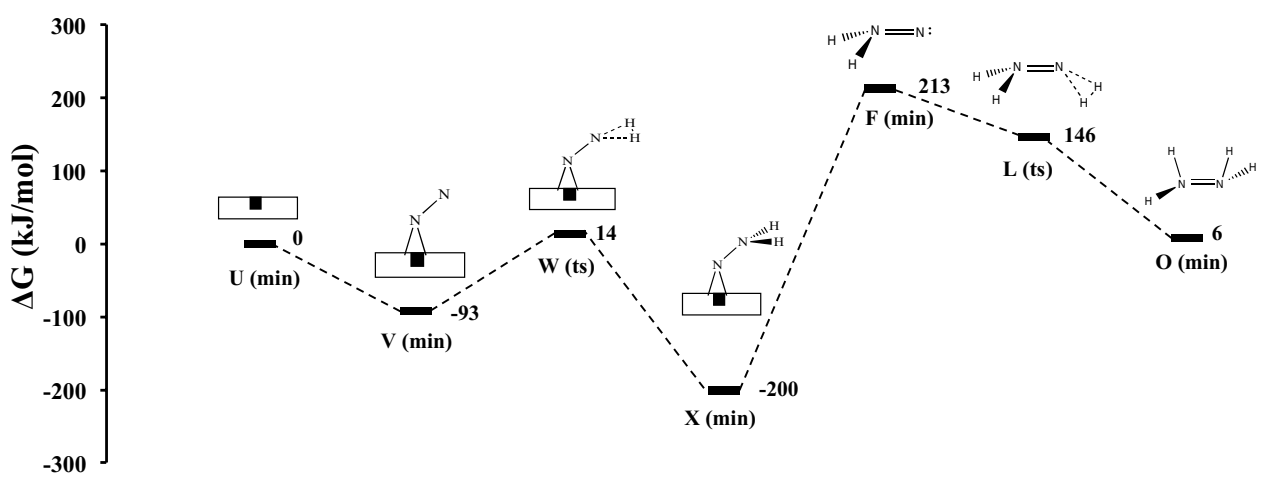

Reaction coordinate

Fig. 2 Gibbs free energy diagram of heterogeneous mechanism occurring on $\mathrm{Co}_{3} \mathrm{Mo}_{3} \mathrm{~N}$ in the presence of nitrogen vacancies (black square). $\mathrm{XC}$ : revPBE $(650 \mathrm{eV})$ for the surface mechanism and B3LYP/aug-cc-pVTZ for the gas phase steps. The choice of these XC functionals is justified based on the mean-average-percent-error that various GGA and hybrid-GGA functionals have in evaluating bonddissociation enthalpies in the supporting information of Ref. [12]. $\mathrm{P}=1 \mathrm{~atm}$ and $\mathrm{T}=298.15 \mathrm{~K}$. Structures of the surface reactions on $\mathrm{Co}_{3} \mathrm{Mo}_{3} \mathrm{~N}$ are shown in Fig. 3

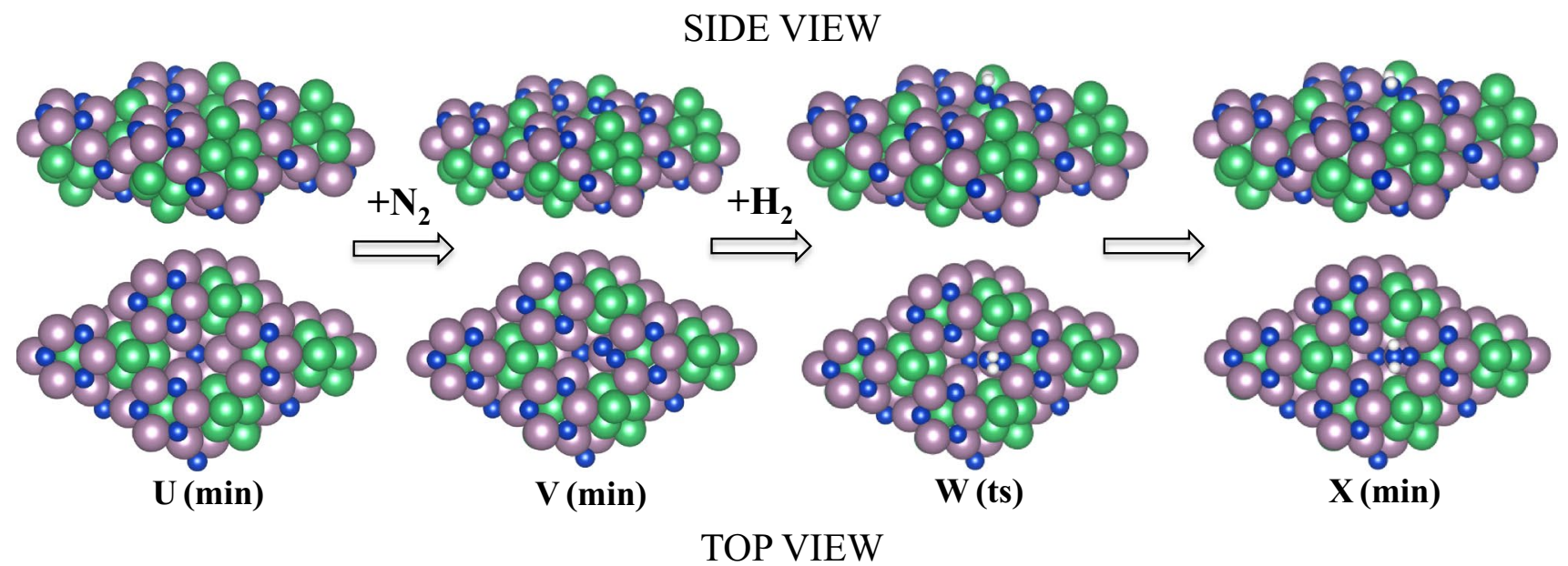

Fig. 3 Sphere-in-contact models of the Eley-Rideal surface reaction of $\mathrm{N}_{2}$ and $\mathrm{H}_{2}$ on $\mathrm{Co}_{3} \mathrm{Mo}_{3} \mathrm{~N}$ in the presence of a nitrogen vacancy. Nitrogen: blue, cobalt: green, molybdenum: pink and hydrogen: white

exothermic than nitrogen chemisorption. Once intermediate $\mathbf{X}$ is formed on the catalyst surface, from the free energy diagram shown in Fig. 2, we see that the energy required to achieve its desorption is relatively high but still much lower than the barrier of the gas phase mechanism $(730 \mathrm{~kJ} /$ $\mathrm{mol}$ ). Therefore some decomposition of intermediate $\mathbf{X}$ back to the reactants $\mathrm{N}_{2}$ and $\mathrm{H}_{2}$, should be expected as this is observed also over $\mathrm{MoN}_{\mathrm{x}} / \gamma-\mathrm{Al}_{2} \mathrm{O}_{3}$ [35] and activated carbon supported tungsten carbide [36]. Once $\mathrm{NNH}_{2}$ is in the gas phase (i.e. intermediate $\mathbf{F}$, a small desorption barrier has been ignored) it reacts in a barrierless process with $\mathrm{H}_{2}(\mathrm{~g})$ as shown in Fig. 2. It is noted that $\mathrm{NNH}_{2}$ can also undergo surface hydrogenation reactions which lead to the formation of ammonia rather then hydrazine. Through this newly suggested mechanism the synthesis of hydrazine is possible on $\mathrm{Co}_{3} \mathrm{Mo}_{3} \mathrm{~N}$ with a relative barrier of the RDS of only $213 \mathrm{~kJ} / \mathrm{mol}$, which is $517 \mathrm{~kJ} / \mathrm{mol}$ lower than the gas phase associative mechanism for hydrazine synthesis. It is therefore suggested that this Eley-Rideal synthesis of hydrazine should be tested under the conditions described with the $\mathrm{Co}_{3} \mathrm{Mo}_{3} \mathrm{~N}$ catalyst.

To summarise, our DFT study shows that hydrazine can be formed with relatively small energy input $(213 \mathrm{~kJ} / \mathrm{mol})$ on $\mathrm{Co}_{3} \mathrm{Mo}_{3} \mathrm{~N}-(111)$ surfaces, compared to the gas phase mechanism which requires $730 \mathrm{~kJ} / \mathrm{mol}$ for the associative mechanism. The free energy diagrams presented are critical for the design of new experiments to show the possibility of hydrazine synthesis from $\mathrm{N}_{2}$ and $\mathrm{H}_{2}$. The infrared absorption frequencies presented of the various ammonia synthesis intermediates are necessary for spectroscopic 
identification of the reaction intermediates. We therefore anticipate that this study will initiate experimental efforts to establish a heterogeneous catalytic route for the synthesis hydrazine.

Acknowledgements We are grateful for useful discussions with Dr. Justin Hargreaves.

Funding No competing financial interests have been declared. The authors acknowledge EPSRC funding (EP/L02537X/1, EP/ L000202/1).

Open Access This article is distributed under the terms of the Creative Commons Attribution 4.0 International License (http:// creativecommons.org/licenses/by/4.0/), which permits unrestricted use, distribution, and reproduction in any medium, provided you give appropriate credit to the original author(s) and the source, provide a link to the Creative Commons license, and indicate if changes were made.

\section{References}

1. Schirmann J-P, Bourdauducq P (2002) Hydrazine. In: Ullmann's encyclopedia of industrial chemistry. Wiley, Weinheim

2. Haber F (1922) Naturwissenschaften 10:1041-1049

3. Haber F (1923) Naturwissenschaften 11:339-340

4. Smil V (2004) Enriching the earth: Fritz Haber, Carl Bosch, and the transformation of world food production. MIT Press, Cambridge

5. Saadatjou N, Jafari A, Sahebdelfar S (2015) Chem Eng Commun 202(4):420-448

6. Ritz J, Fuchs H, Perryman HG (2000) Hydroxylamine. Ullmann's Encyclop Ind Chem

7. Boisen A, Dahl S, Jacobsen CJH (2002) J Catal 208(1):180-186

8. Jacobsen CJH (2000) Chem Commun 12:1057-1058

9. Jacobsen CJH, Dahl S, Clausen BS, Bahn S, Logadottir A, Nørskov J (2001) J Am Chem Soc 123:8404-8405

10. Kojima R, Aika K-I (2000) Chem Lett 29(5):514-515

11. Kojima R, Aika K-I (2001) Appl Catal A 215:149-160

12. Zeinalipour-Yazdi CD, Hargreaves. JSJ, Catlow CRA (2015) J Phys Chem C 119:28368-28376
13. Zeinalipour-Yazdi CD, Hargreaves JSJ, Catlow CRA (2016) J Phys Chem C 120:21390-21398

14. Abghoui Y, Garden AL, Hlynsson VF, Bjorgvinsdottir S, Olafsdottir H, Skulason E (2015) Phys Chem Chem Phys 17:4909-4918

15. Abghoui Y, Garden AL, Howat JG, Vegge T, Skulason E (2016) ACS Catal 6:635-646

16. Abghoui Y, Skúlason E (2016) Catal Today 6(2):635-646

17. Michalsky R, Pfromm PH, Steinfeld A (2015) Interface Focus 5:20140084

18. Michalsky R, Avram AM, Peterson BA, Pfromm PH, Peterson AA (2015) Chem Sci 6:3965-3974

19. Hill PJ, Doyle LR, Crawford AD, Myers WK, Ashley AE (2016) J Am Chem Soc 138(41):13521-13524

20. Hoffman BM, Dean DR, Seefeldt LC (2009) Acc Chem Res 42:609-619

21. Siegbahn PEM (2016) J Am Chem Soc 138(33):10485-10495

22. Gaussian 09 RC, Frisch MJ, Trucks GW, Schlegel HB, Scuseria GE, Cheeseman JR, Scalmani G, Barone V, Mennucci B, Petersson GA et al (2009) Gaussian Inc., Wallingford CT

23. Becke AD (1993) J Chem Phys 98:5648-5652

24. Lee C, Yang W, Parr RG (1988) Phys Rev B 37:785-789

25. Woon DE, Dunning TH Jr (1993) J Chem Phys 98:1358-1371

26. Wilson A, van Mourik T, Dunning TH Jr (1997) J Mol Struct 388:339-349

27. Peterson KA, Woon DE, Dunning TH Jr (1994) J Chem Phys 100:7410-7415

28. Kendall RA, Dunning TH Jr, Harrison RJ (1992) J Chem Phys 96:6796-6806

29. Dunning TH Jr (1989) J Chem Phys 90:1007-1023

30. Peng C, Schlegel HB (1993) Isr J Chem 33:449-454

31. Peng C, Ayala PY, Schlegel HB, Frisch MJ (1996) J Comput Chem 17:49-56

32. Rittle J, Peters JC (2016) J Am Chem Soc 138(12):4243-4248

33. Del Castillo TJ, Thompson NB, Peters JC (2016) J Am Chem Soc 138(16):5341-5350

34. Studt F, Tuczek F (2005) Angew Chem Int Ed 44:5639-5642

35. Chen X, Zhang T, Xia L, Li T, Zheng M, Wu Z, Wang X, Wei Z, Xin Q, Li C (2002) Catal Lett 79:21-25

36. Sun J, Zheng M, Wang X, Wang A, Cheng R, Li T, Zhang T (2008) Catal Lett 123:150-155

37. Miyahara K (1984) J Res Inst Catal 32:1-18 